\title{
En noviembre la Facultad de Arquitectura y Urbanismo de la Universidad de Chile será sede del X Congreso lberoamericano de Gráfica Digital SIGraDi 2006
}

Pedro Soza R. *

SIGraDi, la Sociedad Iberoamericana de Gráfica Digital, agrupa a arquitectos, diseñadores y artistas vinculados a los medios digitales, y constituye la contraparte de organizaciones similares en Europa (eCAADe), Norteamérica (ACADIA) y Asia/Oceanía (CAADRIA) y Medio Oriente (ASCAAD). Desde el año 1997, SIGraDi realiza un Congreso Anual, en el cual se debaten las últimas aplicaciones, posibilidades y desarrollos de las tecnologías digitales aplicadas al Arte, la Arquitectura, el Diseño, el Urbanismo, la Planificación Territorial y el Patrimonio, contando siempre con la participación de relevantes especialistas internacionales. Los congresos de SIGraDi se han efectuado desde 1997 en Buenos Aires, 1998 en Mar del Plata, 1999 en Montevideo, 2000 en Río de Janeiro, 2001 en Concepción, 2002 en Caracas, 2003 en Rosario, el 2004 en Sao Leopoldo y el 2005 en Lima.

El 21, 22 y 23 de noviembre, como sede, esperamos la visita de alrededor de 250 académicos y profesionales de todo el mundo vinculados a estas áreas. A la fecha, hemos recibido solicitudes para evaluar más de 220 investigaciones, en los tres idiomas oficiales del congreso, Español, Inglés y Portugués, que postulan a los 120 cupos disponibles, tanto para el ciclo de exposiciones, como para ser parte del libro oficial de ponencias 2006, que la Facultad editará. En estos momentos, estos trabajos están siendo evaluados por el comité científico internacional que cuenta para este año con 124 miembros (en los tres idiomas).

* Coordinador General X Congreso Iberoamericano SIGraDi 2006 
El Ilamado que la Facultad ha hecho, después de 40 años de desarrollo desde que por primera vez se usaron tecnologías digitales al servicio del diseño, quiere volver la mirada sobre muchas de las preguntas originales acerca del sentido del uso de los medios digitales en el ámbito del Diseño, del Arte, de la Creación y de la Planificación, actividades que nos unen transversalmente.

La pregunta fundamental sigue en pie: ¿Toda este avance tecnológico ha propiciado un mejor diseño, una mejor planificación, una mejor obra de arte? La respuesta a esta pregunta aún es una incógnita.

Por esto hemos centrado el tema del congreso 2006 en un factor que pensamos es el gatillante de todas las motivaciones posibles, donde comienzan y terminan nuestras inquietudes como académicos y profesionales. El Factor Humano.

El X Congreso Iberoamericano de Gráfica Digital ha dado cabida a las siguientes aproximaciones:

\section{EL FACTOR HUMANO}

Creatividad y medios digitales: visión futura

Aprendizaje en el mundo digital

Desarrollo de interfaces

Interacción humano-computadores

\section{TEORÍA Y EDUCACIÓN}

Implementaciones educativas y colaborativas

Metodologías e instrumentos proyectuales

Multidisciplinariedad y transversalidad disciplinar

\section{TEORÍA Y PROCESOS DE DISEÑO}

Diseño y comunicación

Diseño digital y fabricación

Aplicaciones profesionales

\section{MEDIO AMBIENTE, PRESERVACIÓN \\ Y SUSTENTABILIDAD}

Patrimonio, Urbanismo, Ciudad

y Territorio

Sistemas de información

Geográficos

\section{ARTE Y CULTURA DIGITAL}

Desarrollo multimedial

experimental

Instalaciones inmersivas

Video digital

Finalmente, nos complace anunciar que tendremos como invitados especiales a los profesores Charles Eastman, Michel Batty, Thomas Kvan y John Frazer y como representante local al Profesor Eduardo Lyon. Serán tres días de exposiciones y discusión de los trabajos seleccionados en los cuales la integración disciplinar, el trabajo colaborativo y la formulación de nuevas estrategias organizacionales basadas en TIC's son relevantes, contribuyendo de este modo al perfeccionamiento de las diferentes disciplinas del diseño, la planificación y el arte.

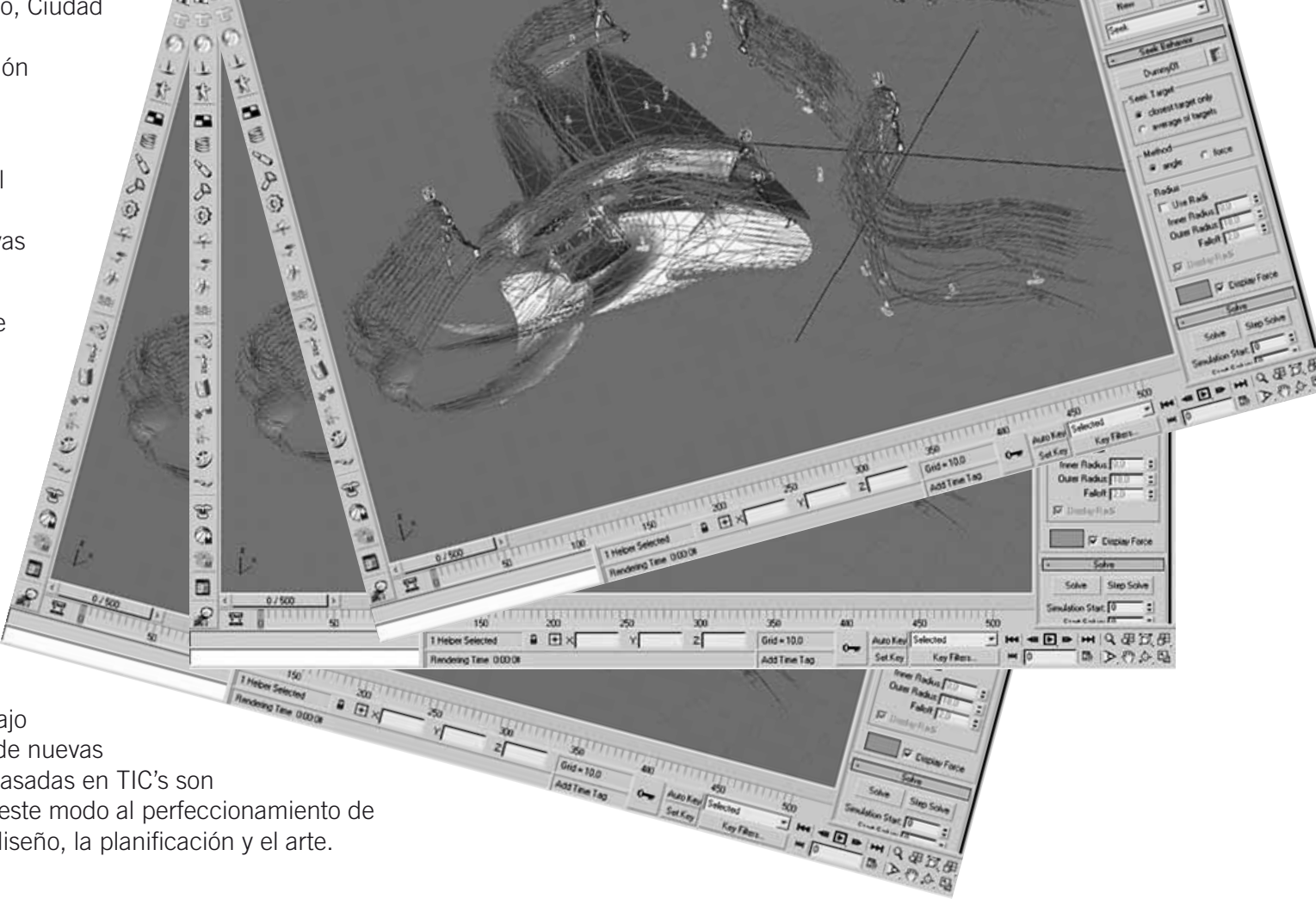

